\title{
COMERCIO JUSTO: Una alternativa comercial sostenible y respetuosa con los Derechos Humanos
}

\author{
David COMET HERRERA \\ Iniciativas de Economía Alternativa y Solidaria (IDEAS) \\ david.comet@ideas.coop
}

FAIR TRADE: A sustainable and respectful commercial alternative to Human Rights

Resumen: El proceso de globalización y deslocalización de la producción mundial ha provocado que las personas consumidoras estén cada vez más ajenas y alejadas de la realidad que viven las personas que participan de la fase de producción y fabricación de los bienes de consumo. Esta situación ha provocado que prevalezcan los intereses propios de unos y otros en la cadena comercial, dejando los intereses comunes en un lugar secundario. Así el Comercio Justo viene a denunciar las situaciones de explotación, desigualdad e insostenibilidad asociados a la cadena comercial y a recuperar, en el terreno del comercio internacional, la solidaridad entre el consumo y la producción, haciendo prevalecer intereses comunes como los de respeto a los Derechos Humanos, en especial, los asociados al "trabajo decente" o la apuesta por un modelo de Desarrollo Sostenible.

Abstract: The process of globalization and outsourcing of world production has caused consumers are increasingly alienated and distant from the reality lived people involved in the production phase of consumer goods. This situation has caused that personal interests prevail of each other in the supply chain, leaving common interests at secondary site. The Fair Trade movement denounces the situations of exploitation, inequality and unsustainability associated with the supply chain and hopes to recover, in the field of international trade, the solidarity between the consumption and the production by through the prevalence of the common interests as respect for human rights, especially those associated with the "decent work" or betting on a model of sustainable development.

Comercio Justo. Derechos Humanos. Desarrollo Sostenible. Cadena de Suministro. Comercio

Palabras clave: Internacional

Fair trade. Human Rights. Sustainable Development. Supply Chain. Intenational Trade 


\title{
1. Introducción: El comercio justo, un sistema para erradicar la pobreza y una forma de Desarrollo Sostenible
}

El Comercio Justo trata de responder a dos retos fundamentales: por un lado, un mayor equilibrio del comercio mundial en beneficio de los actores más desfavorecidos, de manera que tanto la producción como la transformación generen un impacto positivo dentro de las economías locales. En segundo lugar, un efecto demostrativo, constituir una realidad práctica de que otro comercio es posible, que logre concienciar a los consumidores, empresas y administraciones sobre una manera alternativa de afrontar las relaciones comerciales en el ámbito internacional y local. Instituciones tan relevantes como el Parlamento Europeo lo reconocieron como:

\begin{abstract}
"un instrumento importante para la reducción de la pobreza y el desarrollo sostenible, y considera que, a largo plazo, podría facilitar una participación equitativa de los países en desarrollo en el sistema de comercio multilateral, garantizarles un acceso estable y sostenible al mercado europeo y aumentar la sensibilización de los consumidores" 1 .
\end{abstract}

Con ello se ponía en valor como alternativa comercial que evitara todas las problemáticas asociadas al comercio internacional vinculado al proceso de globalización económica.

Entre sus principales ventajas está que ofrece un método sencillo y directo para mejorar la situación de los productores de los países en vías de desarrollo. Así, por un lado, desde la perspectiva de los pequeños grupos de productoras y productores, es una vía que facilita estructuras productivas y organizativas democráticas que priman condiciones sociales, laborales y medioambientales dignas y sostenibles, que promueven el beneficio comunitario al garantizar condiciones comerciales favorables con relaciones de cooperación comercial a largo plazo, y que facilita una remuneración que permite una vida y un trabajo digno para los productores.

Por otra parte, desde la perspectiva de los consumidores, es una manera sencilla de convertirse en agentes de desarrollo al poder optar por productos que tengan garantía social, solidaria y ecológica.

Desde el punto de vista de las Administraciones Públicas, la opción por el Comercio Justo es una alternativa de máxima coherencia con los compromisos internacionales a favor del desarrollo sostenible y la reducción de la pobreza.

De la misma manera, ofrece una alternativa sostenible para las empresas permitiendo mejorar su ética empresarial y participar como agentes de transformación económica y social. Todo ello significa que, al comprar un producto de Comercio Justo, la Administración, los consumidores y las empresas desempeñan un papel importante en la reducción de la pobreza y la creación de unas condiciones de vida dignas a partir de las sencillas transacciones que hacemos a diario.

\section{Orígenes del "Comercio, No Ayuda"}

Fue en 1964 durante la Conferencia de UNCTAD cuando se oyó por primera vez el grito de "Comercio, No Ayuda". En aquel momento, los países altamente industrializados eludían problemas vitales tales como el precio de las materias primas y la apertura de los mercados, centrando sus actuaciones sobre los países del Sur en la concesión de créditos y ayuda oficial para el desarrollo. Durante la segunda Conferencia de la UNCTAD en 1968, los países en

1 Informe del Parlamento Europeo sobre Comercio Justo y Desarrollo (procedimiento 2005/2245 (INI)) aprobado el 6 de julio de 2006 . 
desarrollo volvieron a reivindicar un comercio más justo, pero el resto del mundo hizo caso omiso a sus exigencias.

En la Europa de los 60, los problemas Norte-Sur fueron recogidos por diferentes colectivos que empezaron a protestar contra el comercio internacional y la desigual repartición del poder. Entre estos grupos, nació la idea de crear tiendas "UNCTAD" para vender productos del entonces denominado Tercer Mundo, cuya entrada en el mercado europeo era obstaculizada por los aranceles y otros obstáculos a la importación.

En abril de 1969, la primera "tienda solidaria" se inaugura en el pueblo holandés de Breukelen. Fue el inicio de un periodo de rápido crecimiento, pues en tan solo dos años los Países Bajos ya poseían 120 tiendas de este tipo y el movimiento se difundió rápidamente en Alemania, Suiza, Austria, Francia, Suecia, Gran Bretaña y Bélgica. Con la apertura de las tiendas de Comercio Justo, la artesanía como gama de productos empieza a demandarse cada vez más.

En la década de los 70, tiene lugar un debate ideológico sobre los objetivos del Comercio Justo, y se plantea la venta de productos no como un objetivo en sí mismo, sino como una manera de dar información y concienciar a la población. El resultado fue la conversión de las tiendas solidarias a sedes de las campañas y acciones sociales del movimiento de Comercio Justo.

En los años 80 cambia la perspectiva y se le vuelve a otorgar tanta importancia a la venta como a las campañas y la educación en el Norte. El desarrollo de nuevos productos y la mejora de la calidad empiezan a ganar importancia, y es el momento en que se comienza a trabajar en la creación de una variedad de artículos con los grupos productores y en temas como el marketing o la comunicación para llamar la atención del consumidor. Se crea la Asociación Internacional del Comercio Justo (hoy Organización Mundial del Comercio Justo).

En los años 90 se crea la certificadora de productos FLO-CERT para dar la posibilidad a las empresas convencionales para que puedan incorporar el Comercio Justo en su actividad. Desde entonces, el Comercio Justo ha tenido un crecimiento sostenido en todo el mundo.

\section{Los beneficios para los grupos productores de los países en vías de desarrollo}

El primer estudio sobre impacto (Hopkins, 2000) analizó en el año 1999 la incidencia del Comercio Justo sobre las condiciones de vida en 18 grupos productores de artesanía de América Latina (Perú, Salvador, Guatemala), Asia (India, Filipinas, Bangladesh) y África (Ghana), valorando los siguientes aspectos:

- Ingresos y condiciones de vida.

- Fortalecimiento de capacidades.

- Género.

- Medio ambiente.

Las conclusiones del estudio fueron las siguientes:

1. Los grupos analizados obtenían un $28 \%$ más de ingresos por su actividad en Comercio Justo que en otras actividades alternativas en el mercado local.

2. Existe una mejora en la adquisición del capital físico: talleres, maquinaria, equipamiento, electrodomésticos para el hogar.

3. Mejora real en la educación de los hijos e hijas.

4. Mejora en el fortalecimiento de las capacidades: un $88 \%$ de los grupos recibieron formación en diseño y desarrollo de producto y un $19 \%$ de los grupos recibieron formación en género.

5. Impacto en género: el trabajo en Comercio Justo se percibe como un trabajo seguro y respetable para la mujer. Puede combinar su rol familiar con su rol productivo, incrementando el protagonismo de las mujeres: autoestima, 
participación y control de sus propias vidas.

6. Impacto en medio ambiente: desarrollo de programas de protección al medio ambiente en su actividad productiva. Preocupación por el efecto en el medio ambiente del incremento de la producción.

7. Destino de las ventas: $75 \%$ a organizaciones de Comercio Justo, $21 \%$ de las ventas al mercado local y $4 \%$ de las ventas al mercado tradicional de exportación.

La publicación de este estudio confirmó que el Comercio Justo a largo plazo genera un incremento de ingresos, un incremento de las capacidades de los grupos y consecuentemente una mejora en las condiciones de vida de la comunidad. Asimismo supuso una toma de conciencia de la excesiva dependencia que podía crearse entre los productores y las organizaciones de Comercio Justo, poniéndose un mayor énfasis a partir de entonces en la capacitación y la búsqueda de nuevos clientes fuera de las redes de Comercio Justo y especialmente en el enfoque hacia el mercado local, que se ha traducido en la creación de tiendas de Comercio Justo en el Sur dirigidas a la población del entorno y al turismo.

Además, el Parlamento Europeo indicó en la Resolución "Comercio Justo y Desarrollo" el beneficio que supone el Comercio Justo en términos comerciales, y también en términos de capacitación y asistencia técnica, la seguridad del ingreso, el comercio directo y la facilitación de crédito, siendo estos últimos impactos incluso más significativos. Muchos estudios indican asimismo una mejora del nivel educativo, la conservación de culturas indígenas y otros beneficios sociales. Se da, por otra parte, un efecto "contagio" hacia productores no integrados en el sistema del Comercio Justo (prácticas, precio, relación comercial, beneficio comunitario, etc.).

Según la Organización Mundial para la Agricultura y la Alimentación de las Naciones Unidas (FAO por sus siglas en inglés) en su estudio denominado Las normas sociales y ambientales, la certificación y el etiquetado de cultivos regionales (Danker, 2004) señala que

"en todos los casos que involucran a cooperativas de agricultores, es claro que la prima en el precio del comercio justo es sólo una parte, y con frecuencia pequeña, de los beneficios totales derivados del sistema. El éxito de la autogestión parece ser más importante, y se manifiesta en mejores posiciones de negociación, mejor credibilidad para la obtención de crédito y economías de escala. El sistema de comercio justo contribuye a lograr estos éxitos a través del fomento de la capacidad, de un mercado inicial asegurado, de nexos con el mercado internacional y del aprendizaje en la práctica de la exportación. Aún más, y al igual fue en los casos de comercio orgánico, el comercio justo contribuyó a mejorar la calidad del producto. En el análisis y de manera ideal, uno quisiera separar la contribución del sistema de mercadeo del comercio justo de la contribución que dan las actividades adicionales de apoyo al desarrollo. $\mathrm{Si}$ los beneficios se derivaran principalmente del sistema de mercadeo, sería deseable lograr un incremento en el mercado de los productos del comercio justo. Si, por el contrario, los beneficios resultaran principalmente de las actividades adicionales de apoyo, se podría también reproducir el enfoque de estas actividades sin la necesidad del comercio justo. No obstante, parece que ambos se apoyan mutuamente y están sumamente entrelazados."

\section{Los principios de Comercio Justo}

Como se ha indicado anteriormente, el Comercio Justo ofrece un método para mejorar la situación de los productores de los países en vías de desarrollo, y ha de cumplir los criterios 
El Parlamento Europeo, en su Resolución sobre Comercio Justo y Desarrollo [2005/2245 (INI)] aprobada en Julio de 2006, hace referencia en su apartado 2 al conjunto de criterios que se deben de cumplir el Comercio Justo, y que textualmente dice:

" a) un precio justo al productor, que garantice unos ingresos justos y que permita cubrir unos costes sostenibles de producción y los costes de subsistencia; este precio debe igualar, por lo menos, al precio y la prima mínimos definidos por las asociaciones internacionales de comercio justo,

b) parte del pago se debe de efectuar por adelantado, si el productor así lo solicita,

c) una relación estable y a largo plazo con los productores, así como la intervención de éstos en el establecimiento de normas de comercio justo,

d) transparencia y rastreabilidad en toda la cadena de abastecimiento, a fin de garantizar una información adecuada al consumidor,

e) unas condiciones de producción que respeten los ochos convenios fundamentales de la Organización Internacional del Trabajo (OIT),

f) el respeto del medio ambiente, la protección de los derechos humanos, en particular de los derechos de las mujeres y niños, así como el respeto de los métodos de producción tradicionales que favorezcan el desarrollo económico y social,

g) programas de desarrollo de capacidades y capacitación para los productores, en especial para los pequeños productores marginales de los países en desarrollo, para sus organizaciones y para sus respectivas comunidades, a fin de garantizar la sostenibilidad del comercio justo,

h) el respaldo a la producción y la entrada al mercado de las organizaciones de productores,

i) actividades de sensibilización sobre la producción y las relaciones comerciales en el marco del comercio justo, su misión y sus objetivos, y sobre la injusticia reinante en las normas del comercio internacional,

j) el seguimiento y la verificación del cumplimiento de estos criterios, en cuyo marco deber corresponder un importante papel a las organizaciones del hemisferio sur, con miras a una reducción de costes y una mayor participación de las mismas en el proceso de certificación,

k) evaluaciones de impacto periódicas sobre las actividades relacionadas con el comercio justo;

Cuadro 1. Criterios del Comercio Justo aceptados por el Parlamento Europeo (Fuente: Resolución sobre Comercio Justo y Desarrollo [2005/2245 (INI)]

recogidos en el cuadro 1 para que sea calificado como tal. En resumen,

"Los productos de Comercio Justo son los bienes y servicios producidos, comercializados y vendidos de acuerdo a dichos principios de Comercio Justo y, siempre que sea posible, verificados por sistemas de garantía creíbles e independientes".

\section{Los sistemas de acreditación y certificación del Comercio Justo}

Para que la sociedad pueda identificar o diferenciar que productos son comercio justo o no, existen sistemas de acreditación y verificación del Comercio Justo. Los más reconocidos son los siguientes:

- La marca de la Organización Mundial de Comercio Justo (WFTO por sus siglas en inglés) acredita a las Organizaciones de Comercio Justo, que sólo se otorga a aquellas entidades para las que el Comercio Justo es elemento central de su actividad. La WFTO acredita, a través de medios propios, que todas sus entidades miembro cumplen con los principios de Comercio Justo y ello supone una garantía para los consumidores. 


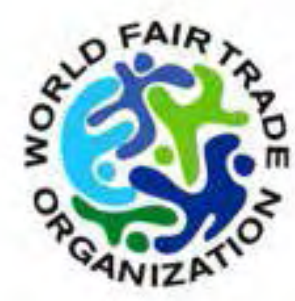

- La estandarización de los principios de Comercio Justo está garantizada a través de varias certificaciones, la de mayor conocimiento y trayectoria es el sello Fairtrade, gestionado por FLO-CERT. El sello Fairtrade está disponible para una gama limitada de productos, fundamentalmente alimentación, y también para flores, balones y algodón. El uso del sello está abierto tanto a Organizaciones de Comercio Justo como a empresas convencionales siempre que cumplan los estándares señalados en la cadena comercial del producto.

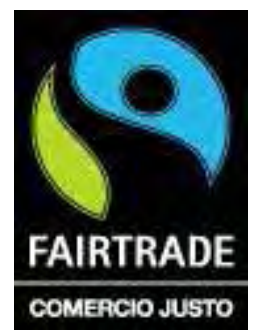

- Otras certificaciones reconocidas, que garantizan el respeto hacia los estándares de Comercio Justo, son Naturland Fair, EcoCert, Fair for Life y el Símbolo de Pequeños Productores (SPP).

En España, se ha creado la Asociación Nacional del Sello de Comercio Justo para promover la comercialización de productos certificados. Asimismo la Coordinadora Estatal de Comercio Justo está trabajando en un sistema de garantías en línea con el sistema de certificación de organizaciones de WFTO, para supervisar el cumplimiento de los criterios de Comercio Justo por parte de los miembros de la plataforma estatal.

En la web de Asociación Nacional del Sello de Comercio Justo (www.sellocomerciojusto. org) se ofrece al consumidor información sobre los establecimientos donde venden productos de comercio justo certificado en su provincia, y en la web de la Coordinadora Estatal de Comercio Justo (www.comerciojusto.org) se ofrece información sobre las Organizaciones de Comercio Justo existentes en España.

\section{Expectativas del Comercio Justo en España}

El movimiento del Comercio Justo se ha expandido de manera espectacular, y es hoy un movimiento global. Según Raggo et al. (2006) en estos primeros años del siglo XXI se calcula que hay más de cinco millones de personas en África, Asia y América Latina que se benefician del Comercio Justo. La mayoría son organizaciones de pequeños productores y trabajadores.

En los países occidentales el movimiento de Comercio Justo y solidario está compuesto por más de 450 organizaciones importadoras, principalmente en Europa y Estados Unidos. En Europa ya hay unas 3.200 tiendas de Comercio Justo y Solidario y más 75.000 supermercados donde hay disponibles productos de Comercio Justo. El movimiento cuenta con más 
de 2.000 profesionales trabajando en la importación, gestión de tiendas y sensibilización, así como miles de voluntarios (Kier, 2008).

El Comercio Justo ha crecido de forma espectacular. En Europa, que desde los inicios es el principal mercado para los productos de Comercio Justo y llega a representar del 60 al $70 \%$ del volumen mundial del Comercio Justo, ha tenido una tasa de crecimiento anual de un $20 \%$ desde el año 2.000 (UE, 2006). Los europeos/as consumieron 13,42 euros de media de productos de Comercio Justo por habitante en 2014; en el Estado español esa cifra sólo alcanzó los 0,713 euros (CECJ, 2015).

Paralelamente al desarrollo de los mercados maduros de Comercio Justo como los del Reino Unido, Alemania, Holanda o Italia, se han desarrollado iniciativas de Comercio Justo en prácticamente todos los países europeos.

De igual manera ha crecido notablemente el Comercio Justo en América del Norte, Canadá, Japón, Australia y Nueva Zelanda, donde se han multiplicado el número de organizaciones importadoras y el volumen de producto comercializado.

El papel de las Organizaciones ha sido básico para dar a conocer este nuevo modelo a través de campañas informativas, publicitarias, de sensibilización y a través de los puntos de venta. Las tiendas de Comercio Justo constituyen espacios de información y transformación esenciales para el cumplimiento de los fines del Comercio Justo. Sin embargo la verdadera expansión cuantitativa ha ido de la mano de dos factores, por un lado, la incorporación de los productos en los supermercados e hipermercados, y por otro lado, la comercialización de productos certificados Fairtrade por parte de empresas convencionales.

Una demostración de la repercusión del Comercio Justo es el reconocimiento institucional que tiene por parte de las instituciones europeas, de muchos gobiernos nacionales, provinciales y locales. De especial relevancia es la Resolución del Parlamento Europeo sobre Comercio Justo y Desarrollo (aprobada en julio del año 2006) a la que se ha hecho referencia en epígrafes anteriores. Esta resolución destaca el papel vital de las organizaciones de Comercio Justo y recomienda a los Estados miembro tomar un papel activo en el apoyo al Comercio Justo y habilitar mecanismos y medidas de apoyo especialmente a las Organizaciones de Comercio Justo.

A nivel nacional, es muy significativo que la antepenúltima Ley de Contratos del Sector Público del Estado ${ }^{2}$ haya incorporado en su Exposición de Motivos una referencia expresa y entrecomillada al Comercio Justo:

"Sintéticamente expuestas, las principales novedades afectan a la previsión de mecanismos que permiten introducir en la contratación pública consideraciones de tipo social y medioambiental... como son los de acomodación de las prestaciones a las exigencias de un "comercio justo" con los países subdesarrollados o en vías de desarrollo como prevé la Resolución del Parlamento Europeo en Comercio Justo y Desarrollo 2005/2245 (INI)".

Otra evidencia que muestra que el Comercio Justo es una historia de éxito es la actitud de las industrias convencionales. Algunas de ellas son cada vez más sensibles a la influencia de las campañas publicitarias de Comercio Justo sobre el mercado. Y optan por sumarse a las iniciativas de Comercio Justo convirtiéndose en licenciatarios del sello Fairtrade o fomentar el consumo de estos productos en el marco de sus políticas de Responsabilidad Social (RSC). 


\section{Bibliografía}

Coordinadora Estatal de Comercio Justo (CECJ) (2015). El Comercio Justo en España 2014. Sector textil e injusticia comercial. Madrid: Coordinadora Estatal de Comercio Justo.

Dankers, C. (2004). Las normas sociales y ambientales, la certificación y el etiquetado de cultivos comerciales. Roma: FAO.

Hopkins, R. (2000). Impact Assessment Study of Oxfam Fair Trade, Oxford: Oxfam.

Kier, J.M. (2008). Fair Trade 2007: New Facts and Figures from an Ongoing Success Story. A report on Fair Trade on 33 consumer countries. Culemborg: Dutch Association of Worldshops.

Raggo, P., Tremblay, L., Osterhaus, A. (2006). Otra manera de hacer negocios. Los éxitos y los retos del Comercio Just. Bruselas: Fair Trade Advocacy Office.

Sánchez, B., Carreti, M. (2011). Guía para la introducción del Comercio Justo en el sector empresarial. Córdoba: IDEAS.

Unión Europea (2006). Resolución del Parlamento Europeo sobre comercio justo y desarrollo del 6 de julio de 2006. Disponible en: http://www.europarl.europa.eu/sides/getDoc.do?pubRef=-// EP//TEXT+TA+20060706+ITEMS+DOC+XML+V0//ES\&language=ES\#sdocta18 